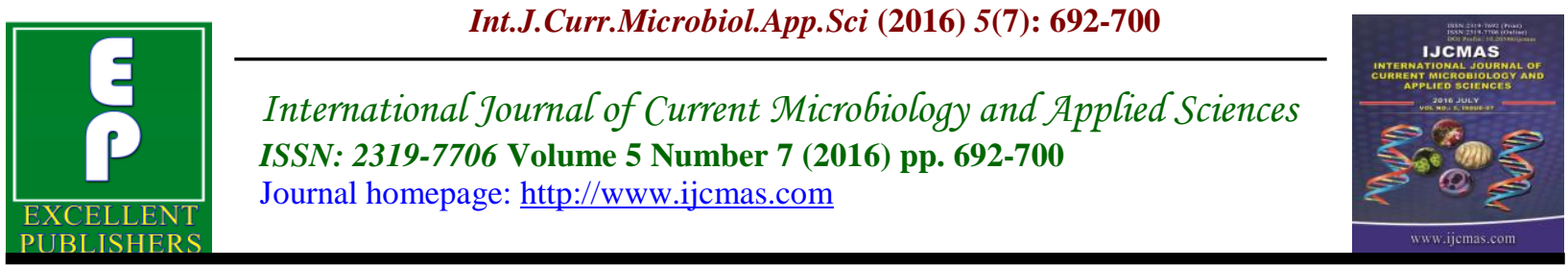

Original Research Article

http://dx.doi.org/10.20546/ijcmas.2016.507.079

\title{
Identification and Diagnosis of Some Pathological Phenomena on the Date Palm caused by Fusarium Species in Iraq
}

\author{
Alyasiri, Ismail Ibrahim ${ }^{*}$, Najat Adnan Saad ${ }^{3}$, Ahmed Zuhair Ismail ${ }^{2}$ and \\ Ahmed Rahim Nasser ${ }^{3}$ \\ ${ }^{1}$ College of Agriculture, University of Misan, Iraq \\ ${ }^{2}$ General of the authority for plant protection, Ministry of Agriculture, Iraq \\ ${ }^{3}$ General of the authority for agricultural researches, Ministry of Agriculture, Iraq \\ *Corresponding author
}

\begin{tabular}{|c|c|}
\hline & A B S T R A C T \\
\hline & \multirow{9}{*}{$\begin{array}{l}\text { It is known that the fungus Fusarium involved in the cases of date palm } \\
\text { inflorescence rot, the results of survey and investigation in the general areas of } \\
\text { cultivation of palm groves in Iraq for the period from } 2005 \text { to } 2011 \text {, isolating and } \\
\text { diagnosis pathogens from soil and plant parts, testing pathogenicity on small plants, } \\
\text { many laboratory and field studies, showing that the main causes of some important } \\
\text { and serious pathological phenomena that spread largely on the palm and caused } \\
\text { death were species of the fungus Fusarium. The results proved that the cases of } \\
\text { yellowing and dries fronds and numbness dates caused by some aggressive races } \\
\text { and toxic metabolites (toxins) of the fungus Fusarium solani, which resides in the } \\
\text { root zone and contributes to the weakness of palm, and make it susceptible to other } \\
\text { vulnerable fungi like Thiealophiopsis paradoxa which cause curvature of the } \\
\text { summit as a results of cellulose analysis. While Fusarium proliferatum and the } \\
\text { toxins produced by this fungus causing the rapid death and dries completely of the } \\
\text { palm (the phenomenon of embalming palm by death of standing palm and drought } \\
\text { summit completely). The fungus moves through xylem vessels in the trunk and kill } \\
\text { them, and prevent the transmission of water, nutrients and leading to decimation } \\
\text { palm during a short period, often the fungus was more active at low temperatures } \\
\text { during winter. }\end{array}$} \\
\hline & \\
\hline & \\
\hline & \\
\hline & \\
\hline & \\
\hline Article Info & \\
\hline & \\
\hline & \\
\hline
\end{tabular}

\section{Introduction}

Since the early nineties of the last century, important pathological phenomena spread in the palm groves in Iraq, a committee of specialists in the ministry of agriculture and other scientific institutions was nominated including the college of agriculture and the atomic energy organization, a number of specialists in plant diseases and insects were involved, and hosting one of the experts from the Maghreb. They recommended that the cause of these phenomena is the fungus Thiealophiopsis paradoxa, and this was compatible with Al-Hassan and Abbas, 1978. The insects team focused on the presence of flies which lay their eggs at the summit, the flies work in harmony with the mentioned fungus on the analysis of 
cellulose, and lead to curvature of summit, and came out a recommendation for the use of fungicides to combat fungus and insecticides to combat the fly and get rid of the palm trees infected cut it off and burn it as a solution to the problem (Zuwein, 1992).

These recommendations continued until 2003, despite the isolation of some Fusarium species by the committee, they neglected the issue and did not account for interest, perhaps to avoid going into the disease and its relationship with the Bayoud disease, that had not been recorded in Iraq, Although there was some papers made up in Iraq and isolate Fusarium species from the date palm (Abbas and Mohi, 1990). The work of the committee was stopped at this point, and because of the circumstances experienced by Iraq in the eighties and the subsequent conditions of the economic blockade, which reflected the negative effects, palm groves suffered much of the deterioration of the service due to lower financial benefits of palm, rising costs of services and cultivating crops with quick returns.

Cases continued to deteriorate rapidly, we had reported yellowing of palm fronds in the beginning of 2002, following by requests from departments of agriculture in all the provinces to report on the phenomenon of numbness of dates taken quickly spread on many important varieties including khastawi, Khadrawi and others, as well as marking a state of complete dryness of palm fronds and death fully palm. We started to work through a comprehensive survey of the palm groves with the help of all workers in the plant protection departments in the provinces to determine the prevalence of these phenomena, and then begin to collect samples of soil, plant parts and isolate pathogens associated with them to determine the relationship of their respective to the pathological cases, and continued to work on the completion of these studies, for the period from 2005 to 2012. We have been noted the relationship between the fungus Fusarium and the pathological cases in the palm, but this was faced objections by the reviewer of the Iraqi agriculture journal in 2005. Based on the complaints submitted to the ministry of agriculture, they had been forming a committee comprising researchers from the faculty of agriculture - university of Baghdad and the general of the authority for agricultural research to study the phenomenon of numbness dates and they recommended several years later that the reason for this phenomenon is due to the circumstances of unknown physiological condition result from thirst and injury of mites.

\section{Materials and methods}

\section{Identifying and diagnosis of injuries}

After conducting a comprehensive survey, determine the pathological phenomena and their extent across the provinces (Alyaseri, et al., 2006), samples had been collected from areas of infection in the provinces which included soil, roots and trunks of the palms. Samples were cultivated on potato dextrose agar (PDA), after superficial sterilization with chlorex solution of $0.05 \%$, dilutions of soil $(1 / 1000, \mathrm{w} / \mathrm{v})$ also were cultivated on potato dextrose agar (PDA), then isolate and purify the fungi from all samples (subcultures) Alexopoulos and Beneke, 1962), after the purification, fungi is being examined under a microscope for the purpose of diagnosis, that made according to the taxonomic keys for each of Booth, 1977, Barnett \& Hunter, 1972, Ellis, 1971, Gilman, 1975, Toussoun \& Nelson, 1968 and Watanabe, 2002. The first diagnosis of the fungus Fusarium proliferatum was according to Sedra Mouly al- Hassan on our presence at the meeting of 
the (Regional Project research for early detection of Bayood disease on the palm and the development of technologies for combating) held in Algeria in 2005.

\section{Pathogenicity test}

Pathogenicity test for all isolates was done using six months age palm seedlings planted in nylon bags, placing one disc $(1 \mathrm{~cm}$ diameter) taking with cork borer from two weeks fungal culture, covered them with soil.

As well as the treatment of ornamental seedlings of Washingtonia and Sykes palm, followed by monitor and record observations and symptoms that appear on them. Then re-isolate the fungus from parts that developed symptoms.

\section{Testing filtrate effect}

Czapex liquid broth in $500 \mathrm{ml}$ flasks were prepared according to Alexopoulos, C.J. and Beneke, E.S. 1962, inoculation by using 1 $\mathrm{cm}$ discs taken from two weeks pure fungal culture, and packaging flasks by using black cover and put them in shaking incubator at a temperature of $25^{\circ} \mathrm{C}$ for one month.

Filtration was on two-step using Buchner suppress, subsequent filtration suppression Includes Millipore filter with a vacuum. Filtrates were distributed in $250 \mathrm{ml}$ flasks, five palm seedlings with six months old placed in all flasks, which included a filtrate of culture with fungi, fungus filtrate without the presence of fungi and comparison treatment (distilled water only) with three replicates, then observations recorded.

\section{Results and Discussion}

Relationship between fungi and
pathological phenomena

Results (table 1) showed that the fungus Fusarium solani was the most frequent in the root zone and cause yellowing of leaves, the strong strains lead to get phenomenon numb dates due to production of fungal toxins that lead to a weakening and killing of xylem vessels and preventing the arrival of sufficient quantities of nutrients and water for the stalks (Figure1). This is agree with Wazir et al., 2014, they showed that the sudden decline disease of date palm is one of the major problems of the region and had destroyed hundreds orchards in Pakistan, caused by six fungi namely, Fusarium solani and other. Mansoori and Kord, 2006 reported a serious disease of date palm caused by $F$. solani associated with yellowing and death of the fronds in Iran. In Iraq, a similar disease symptoms caused by $F$. solani had been reported (Al Yasiri et al., 2010).

The results also showed that the fungus Fusarium proliferatum isolated from palm trees that appear in full dry fronds and die standing (mummified) (Figure 2). Isolation of the fungus from the trunks of palm trees was possible, and was the most frequent in these parts, and this is compatible with K.S. Juber, 2010. It was also observed that the fungus does not reach the upper portions of the affected palm, palm death occurs as a result of secreted fungal toxins that lead to the killing of xylem vessels (Figure 3) and preventing the arrival of water and nutrients to the top. While the fungus Fusarium moniliforme cause only slight yellowing symptoms. Also Mansoori, 2012, Explain that $F$. proliferatum was isolated from the xylem of fruit bunch samples with date bunch fading(DBF) disease in Iran. While Julio Hernandez-Hernandez, et al., 2010, made a survey of diseases caused by Fusarium spp. on palm trees in the Canary Islands, where palm trees growing in both 
gardens and public parks and natural palm groves, showing symptoms of wilt and dieback, $F$. proliferatum occurred in fifteen palms located in Gran Canaria. As well as Armengol et al., 2005 in Spain had identify and study the incidence and characterization of $F$. proliferatum on ornamental palms, Polizzi G. and A. Vitale, 2003, in Italy, indicated that $F$. proliferatum was correlated to the blight on majesty palm. But Hameed, M.A. 2012 had successfully identified that the causal of date palm inflorescence rot disease in southern part of Iraq is $F$. proliferatum and Abdalla et al., 2000.

Also isolated three Fusarium species from infected leaves and roots of the date palm trees, pathogenicity test on date palm seedlings showed that $F$. proliferatum should be regard as a potentially dangerous pathogen of date palm in Saudia Arabia.

\section{Isolation of the fungi}

Fusarium species and other fungi were isolated from most soils samples that were collected, as well as the roots, the more frequent fungi were Fusarium solani, Fusarium proliferatum and Fusarium moniliforme (Table 1) and other facultative fungi that were not responsible for pathogenic phenomena.

\section{Pathogenicity test}

Aggressive Isolates of the fungus $F$. solani led to the emergence of symptoms of yellowing and wilting on the seedling after almost one month, they became very weak and die after about two months. While the symptoms of wilt was clear on the seedling that have been inoculated with $F$. proliferatum isolates and led to the drying and death after one month. This was compatible with Mansoori and Kord, 2006. Also Washingtonia and Sykes seedling have the same symptoms of yellowing and wilting (Figure 4). The isolates of $F$. moniliforme has no effects on all seedlings, but only slight yellowing.

\section{The effect of fungi filtrates}

It was observed that seedlings placed in the $F$. proliferatum filtrate began to wilting after 24 hours, dried up and died three days after. While the seedlings placed in the filtrate of the fungus $F$. solani had been died after about seven days. The cause of seedlings death was attributed to mycotoxins produced by these fungi, the filtrate of strong isolates of $F$. solani on Czapex broth media killed palm seedling of six months age during a short period (Figure 5).

This is agree with Muneera Alkahtani, et al., 2011, studying on F. moniliforme they indicated that Fummonisin was highest toxin in tested date cultivars followed by T-2 and Zeralenone, reduction in quality of date fruits due to loss of their nutrients as the result of biochemical change.

Abdalla, M.Y. et al., 2000, found in Saudi Arabia that all nine $F$. proliferatum strains isolated from diseased plants were shown to belong to mating population D of Gibberella fujikuroi. Finally, the strains were also tested for the production of beauvericin, fumonisin B1, fusaproliferin, fusaric acid, and moniliformin. Also Abbas, H.K. et al. 1999, Studying on rice Fusarium sheath indicated that all 15 isolated of $F$. proliferatum produced Fumonisin B1 (FB1), Fumonisin B2 (FB2), moniliformin (MON) and Beauvericin (BEA) in culture on rice. 
Table.1 Fungi isolated from different parts of the date palm in the provinces

\begin{tabular}{|c|c|c|c|c|c|c|c|c|c|c|}
\hline \multirow[t]{3}{*}{ No } & \multirow[t]{3}{*}{ Provinces } & \multicolumn{9}{|c|}{ Frequency of the fungus Fusarium $(\%)^{* *}$} \\
\hline & & \multicolumn{3}{|c|}{ Fusarium solani } & \multicolumn{3}{|c|}{ Fusarium proliferatum } & \multicolumn{3}{|c|}{ Fusarium moniliforme } \\
\hline & & Soil* & Roots & Trunks & Soil & Roots & Trunks & Soil & Roots & Trunks \\
\hline 1 & Basrah & 0.4 & 5.3 & - & 0.1 & 1.8 & 1.2 & 0.2 & 1.9 & - \\
\hline 2 & Misan & 0.5 & 10.1 & - & 0.0 & 1.1 & 3.1 & 0.1 & 2.6 & - \\
\hline 3 & Dhi Qar & 2.2 & 43.3 & - & 1.9 & 2.9 & 45.1 & 0.8 & 33.6 & - \\
\hline 4 & Samawah & 0.2 & 1.6 & - & 0.5 & 0.3 & 0.9 & 0.5 & 1.1 & - \\
\hline 5 & Diwaniya & 0.7 & 12.9 & - & 0.1 & 1.4 & 4.9 & 0.9 & 5.4 & - \\
\hline 6 & Najaf & 0.8 & 15.2 & - & 0.2 & 1.6 & 7.8 & 1.2 & 10.9 & - \\
\hline 7 & Karbala & 2.3 & 45.6 & - & 1.0 & 3.3 & 66.8 & 2.9 & 40.3 & - \\
\hline 8 & Wasit & 0.4 & 4.8 & - & 0.3 & 1.3 & 1.1 & 3.5 & 4.2 & - \\
\hline 9 & Babylon & 1.4 & 29.8 & - & 1.2 & 2.0 & 25.9 & 3.3 & 28.2 & - \\
\hline 10 & Diyala & 0.3 & 2.1 & - & 0.1 & 0.4 & 1.4 & 2.1 & 2.1 & - \\
\hline 11 & Baghdad & 0.6 & 1.8 & - & 0.2 & 0.5 & 4.8 & 4.5 & 2.5 & - \\
\hline 12 & Anbar & 0.8 & 2.8 & - & 0.4 & 1.3 & 3.9 & 1.3 & 3.2 & - \\
\hline 13 & Salah Al-Din & 1.6 & 35.5 & - & 0.8 & 2.1 & 30.3 & 2.1 & 23.8 & - \\
\hline & The mean & 0.94 & 15.5 & - & 0.52 & 1.54 & 15.2 & 1.8 & 12.3 & - \\
\hline
\end{tabular}

*Soil dilution of $1 / 1000$. **Total frequency of fungi in six treatments with five replicates.

Fig.1 Date numbness caused by Fusarium solani

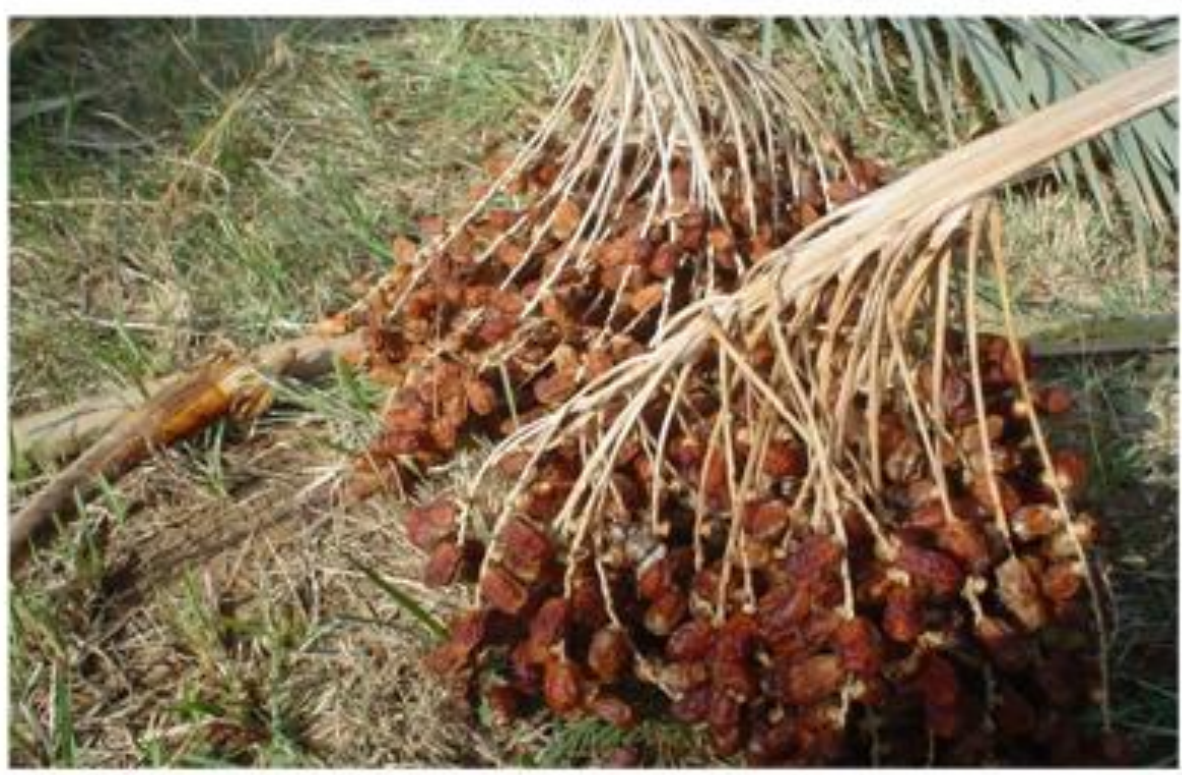


Fig.2 Drying summit caused by Fusarium proliferatum (mummified palms).
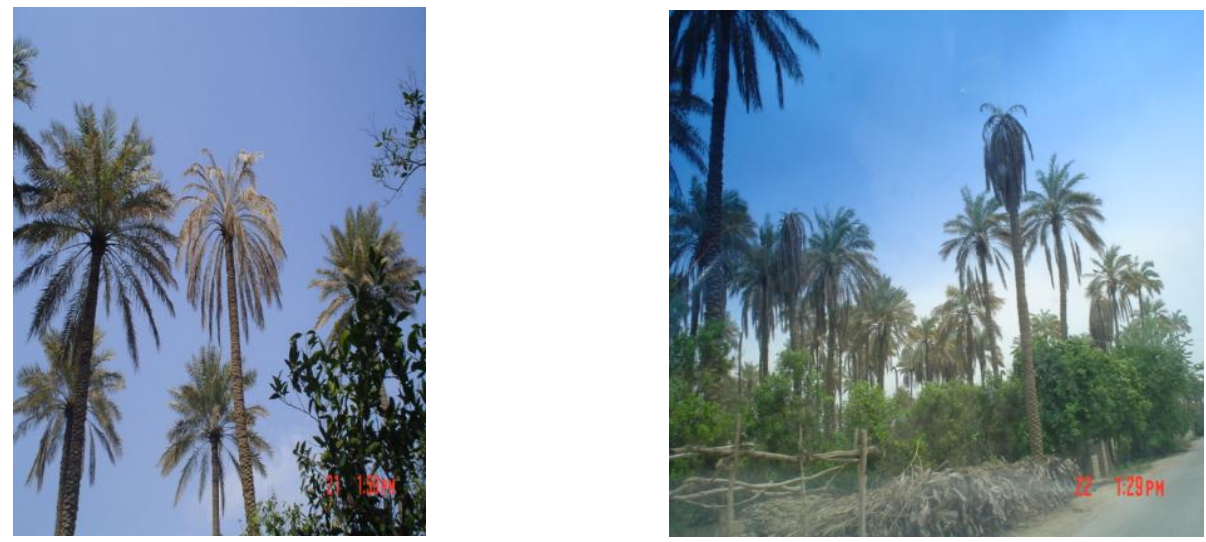

Fig.3 Xylem vessels of (mummified palm), brown and alcohol odor.

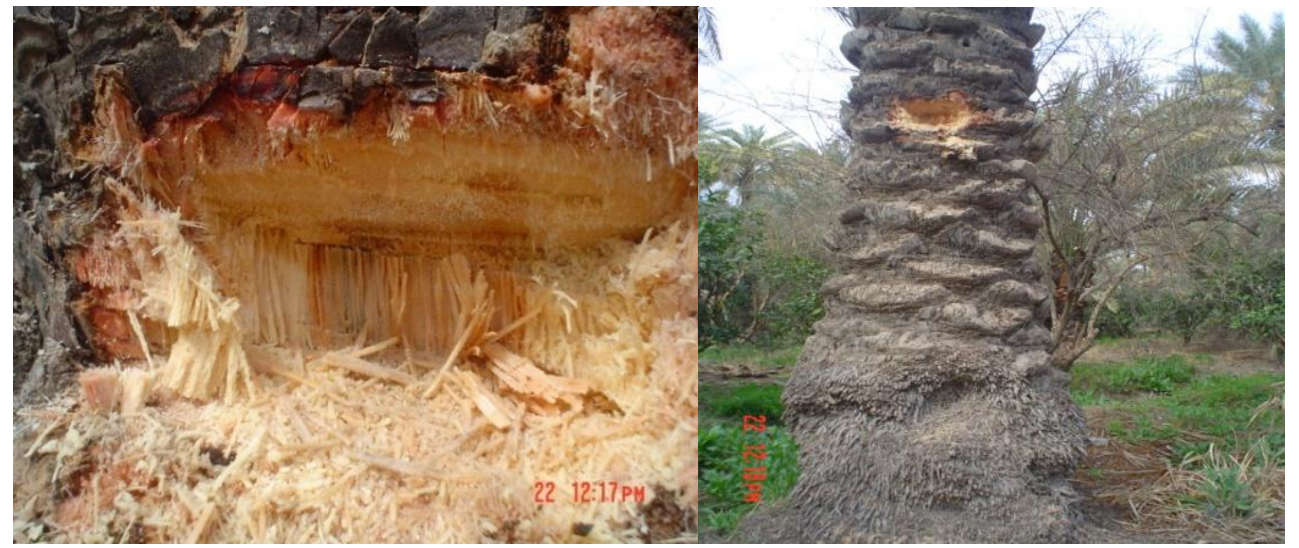

Fig.4 Pathogenecity test (Date palm, Washingtonia and Sykes seedling inoculated with Fusarium isolates).

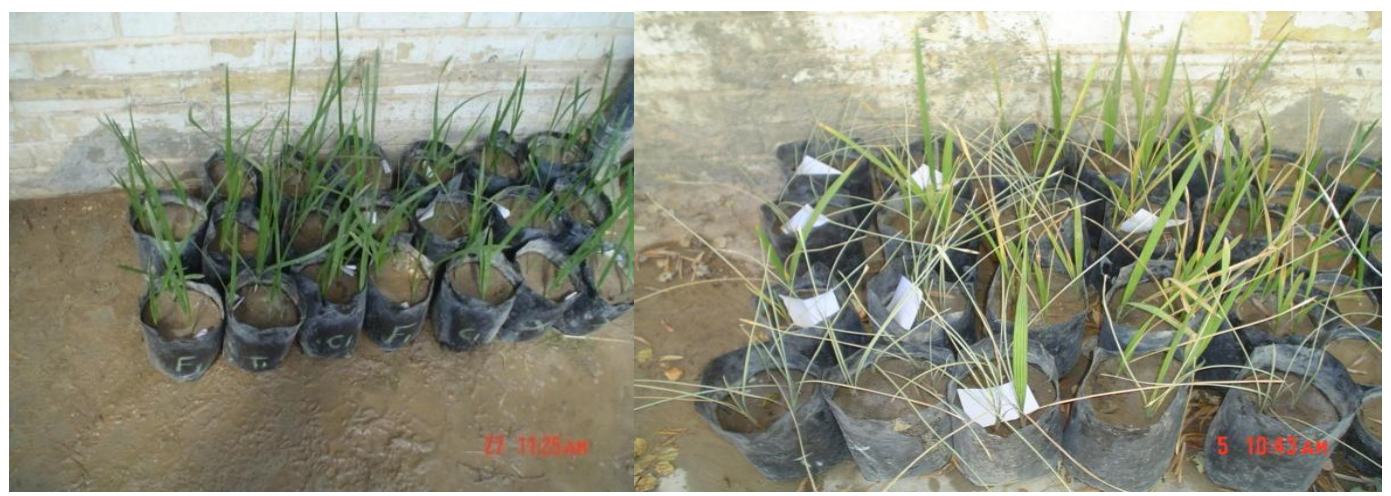




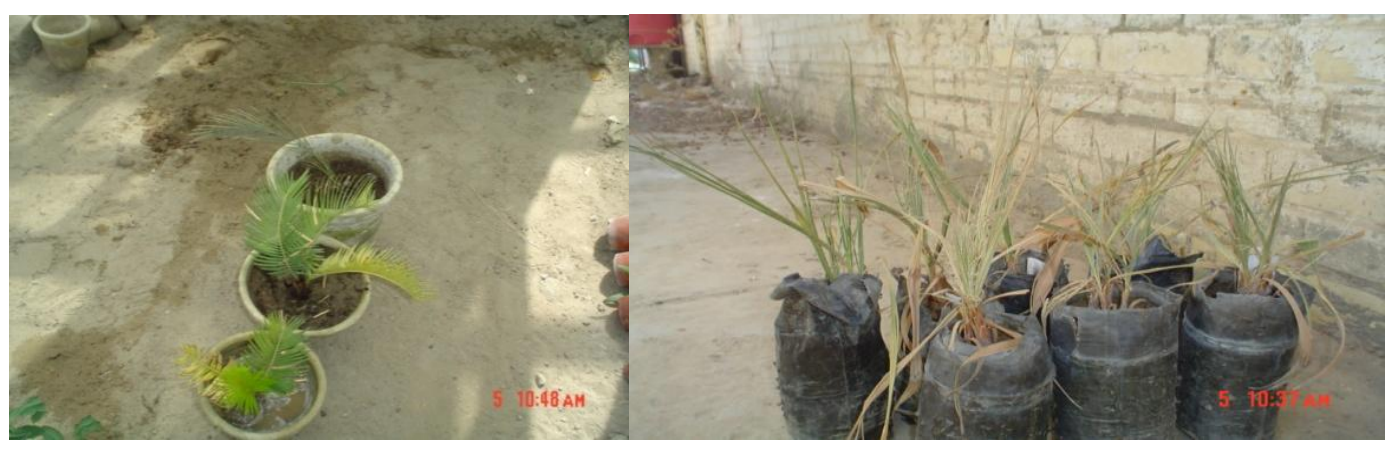

Fig.5 The effect of the fungi filtrate on date palm (6 month seedling).

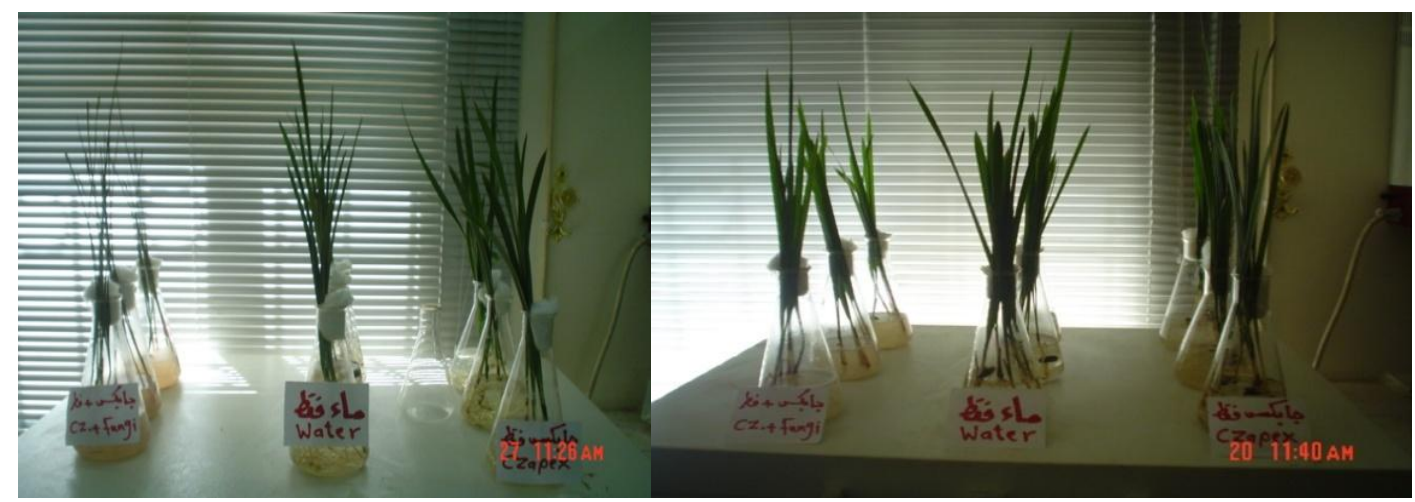

\section{Conclusion and Recommendation}

Fusarium species can be considered as a basic fungi responsible for the degradation of palm groves in Iraq, especially $F$. solani and $F$. proliferatum, and are likely to be the key pest that lead to a weakening, and affecting with other secondary fungi like $T$. paradoxa and Alternaria alternata that were considered by some researchers as a major pathogenic on the palm (Al-Hassan et al., 1978; Ghali, 2001; Zuwein, 1992).

Most of the Iraqi soils contain all Fusarium fungi mentioned, this means for the continuation of pathological cases of yellowish, dry fronds, weakness and death to the date palm. Thus will continue to decrease in number of palm trees during the following years, especially in orchards that suffer from neglect and poor services.
Iraqi soil based on tests conducted by Sedra Moulay Hassan, 2010 has prospective high receptivity to Fusarium oxysporum f.sp. albedinis in most types of palm groves across the provinces.

Iraq need to breeding resistant varieties to the fungi (Fusarium spp.), depending on the seed and wild varieties after studying their resistance to the strong strains and isolates (Aggressive ones).

After getting resistant varieties they must being bred with tissue culture technique, by cooperation with one of the specialized international companies, in order to obtain large numbers of them (mass production), to cultivated for compensation palms in the old orchards and cultivation of new orchards. Also it is important to create a research center dedicated includes advanced devices, technologies mean palm trees and pests, and conduct research and studies on these aspects. 


\section{References}

Abbas, H.K.R.D., Cartwright, W., Xie, C.J., Mirocha, J.L., Richard, T.J., Dvorak, G.L., Sciumbato, W.T., Shier. 1999. Mycotoxin production by Fusarium proliferatum isolates from rice with Fusarium sheath rot disease. Mycopathologia, 147(2): 97-104.

Abbas, I.H., Mohi, M.N. 1990. The presence of some types of fungus Fusarium on the palm trees. Iraqi $J$. Microorganism, 2(2): 49-56.

Abdalla, M.Y., A. Al. Rokibah, A. Moretti and G. Mule. 2000. Pathogenicity of toxigenic Fusarium proliferatum from date palm in Saudi Arabia. Plant Dis., 84: 321-324.

Alexopoulos, C.J. and Beneke, E.S. 1962. Laboratory manual for introductory mycology. Burgess Publishing Company. 199p.

Al-Hassan, K.K. and Abbas, G.Y. 1978. Out-break of terminal bud rot of date palm caused by Thielaviopsis paradoxa. Date Palm J., 5(1): 117119.

Al Yaseri, I.I., Ismail, A.Z and Mohammed, A.A. 2006, A preliminary study on spread of date palm pests in Iraq Ninth Arab Congress of Plant Protection, 1923 November, Damascus, Syria (Abstract).

Alyasiri , I.I., N.A. Saad, A.R. Nasser, S.A. Hassan and K.M. Zaid. 2010. The relationship between the fungus Fusarium solani and some pathological phenomena on date palm trees and the effectiveness of some systemic fungicides for their control. Fourth International Date Palm Conference. Acta Horticulturae Number 882, pp :505-514.

Armengol, A., A. Moretti, G. Perone, J.A. Bengoechea and J. Garica-Jimenez. 2005. incidence and characterization of Fusarium proliferatum on ornamental

Barnett, H.L. and Hunter, B.B. 1972. Illustrated genera of imperfect fungi. Burgess Published Company. 237p.

Booth, C. 1977. Fusarium, laboratory guide to the identification of major species. Common Wealth Mycological Institute. Kew, Surrey England. 58p.

Ellis, M.B. 1971. Dematiaceous hyphomycetes, CMI. Kew, Surrey, England 608p.

Ghali, F.S. 2001. Palm degradation caused by the fungus Chalara paradoxa, conditions of infection and resistance. $\mathrm{Ph}$. D. thesis. College of Agriculture University of Baghdad.

Gilman, C.J. 1957. A manual of Soil fungi. The lowa State University. Press Ames, Lowa, USA. 450P.

Hameed, M.A. 2012. Inflorescence rot disease of date palm caused by Fusarium proliferatum in southern Iraq. African J. Biotechnol., Vol. 11 (35); 8616-8621.

Juber, K.S., D.S.J. Al-Windawi and Rajaa G. Abdul Muhsen. 2010. First record for the fungus Fusarium proliferatum (natsush) Nirenberg on date palm in Babylon governorate. Fourth international date palm conference .Abu Dhabi, UAE.

Julio Hernandez-Hernandez , Espino, Juan Manuel Rodriguez-Rodriguez, PerezSierra, Maela Leon, Palmo Abad-Compos and Josep Armengol. 2010. Survey of diseases caused by Fusarium spp. on palm trees in the Canary Islands. Phytopathol. Mediterr, 49: $84-88$.

Mansoori, B. 2012. Fusarium proliferatum induces gum in xylem vessels as the cause of date baunch fading in Iran. $J$. Agr. Sci. Tech., Vol. 14: 1133-1140.

Mansoori and Kord. 2006. Yellow death: A disease of date palm in Iran caused by 
Fusarium solani. Phytopathol., 154: 125.

Muneera Alkahtani, M.A. El-Naggar, S.A. Omer, Eman, M., Abdel-Kareem and M.I. Ammar. 2011. Effect of toxic Fusarium moniliforme on some biochemical component of some date palm cultivars. American J. Food Technol., 6(9): 730-741.

Polizzi, G. and A. Vitale. 2003. First report of Fusarium blight on majesty palm caused by Fusarium proliferatum in Italy. Plant Dis. 87, 1149.

Sedra, M.H. 2010. Evaluation of soil receptivity of date palm groves in Arab countries to Fusarium oxysporum f.sp. albedinis, causal agent of Bayoud disease of date palm. Fourth International Date Palm Conference. Acta Horticulturae Number 882. pp:515-521.

Sedra, M.H. 2005. Personal communication on our presence at the meeting of the (Regional Project research for early detection of Bayood disease on the palm and the development of technologies for combating) held in Algeria in 2005.

Tousson, T.A. and Nelson, P.E. 1968. Apictoial guide to the identification of Fusarium species. The Pennsylvania State University Press. 51p.

Watanabe, T. 2002. Pictorial atlas of soil and seed fungi. CRC Press. $487 \mathrm{p}$.

Wazir, A., Maitlo, Ghulam, S., Markhand, Adel, A., Abul -Soad, Abdul, M., Lodhi and Mushtaque A. Jatoi. 2014. Fungi associated with sudden decline disease of date palm (Phoenix dactylifera L.) and its incidence at Khairpur, Pakistan. Pakistan J. Phytopayhol., Vol. 26 (01):67-73.

Zuwein, Q.K. 1992. The phenomenon of death of the palm. The Authority of the Agricultural Services. Ministry of Agriculture - Iraq (press extension).

\section{How to cite this article:}

Alyasiri, Ismail Ibrahim, Najat Adnan Saad, Ahmed Zuhair Ismail and Ahmed Rahim Nasser. 2016. Identification and Diagnosis of Some Pathological Phenomena on the Date Palm caused by Fusarium Species in Iraq. Int.J.Curr.Microbiol.App.Sci. 5(7): 692-700. doi: http://dx.doi.org/10.20546/ijcmas.2016.507.079 